\title{
El discurso mediático en las disputas por el aborto en México a nivel subnacional: la mediación movimiento-contramovimiento
}

\author{
The media discourse in abortion disputes in Mexico at the \\ subnational level: movement-countermovement mediation
}

O discurso midiático nas disputas sobre o aborto no México em âmbito subnacional: a mediação movimento-contramovimento

Jairo Antonio López*

\section{RESUMEN}

El presente artículo analiza el discurso mediático acerca del Palabras clave: aborto en Veracruz, México, bajo la perspectiva de la mediación del conflicto movimiento-contramovimiento por los derechos sexuales y reproductivos. A partir de la sistematización de las publicaciones realizadas en torno al aborto por parte de seis medios locales durante 2019 (tres impresos y tres electrónicos), aborto, discurso mediático, mediaciones, movimientos-contramovimientos. se identifica el tipo de acceso y las orientaciones del discurso de las notas publicadas. Se argumenta que los medios locales en Veracruz construyeron un discurso que dio mayor acceso a los actores del contramovimiento que se oponían a los derechos sexuales y reproductivos, con una tendencia a publicar notas que se orientaron hacia la presentación de valoraciones, tomas de posición e ideas negativas sobre el aborto. Los resultados se presentan como un aporte analítico para el estudio de las mediaciones que establecen los medios de comunicación en los conflictos por derechos a nivel subnacional en México, al tiempo que plantea preguntas respecto de los cambios que se pueden dar luego de la despenalización del aborto en Veracruz en 2021.

\footnotetext{
* Migrante. Doctor en Investigación en Ciencias Sociales por la FLACSO-México. Sociólogo por la Universidad de Antioquia, Colombia. Docente e Investigador en la Unidad Académica de Ciencia Política de la Universidad Autónoma de Zacatecas. Zacatecas, México. jairolopez32@gmail.com
} 


\begin{abstract}
This article analyzes the media discourse on abortion in Veracruz, Mexico, from the mediation of the movement-countermovement conflict for sexual and reproductive rights. Based on the systematization of publications on abortion by six local media during 2019 (three print and three electronic), the type of access and discourse orientations of the published articles are identified. We argue that the local media in Veracruz constructed a discourse that gave greater access to counter-movement actors who opposed sexual and reproductive rights, with a tendency to publish stories that presented negative assessments, positions, and ideas about abortion. We deliver our results as an analytical contribution to the study of media mediations in conflicts over rights at the subnational level in Mexico while raising questions about the changes that may occur after the decriminalization of abortion in Veracruz in 2021.
\end{abstract}

\section{RESUMO}

O presente artigo analisa o discurso midiático sobre o aborto em Veracruz, no México, sob a perspectiva da mediação do conflito movimento-contramovimento pelos direitos sexuais e reprodutivos. A partir da sistematização das publicações realizadas em torno ao aborto por seis meios de comunicação locais durante 2019 (três impressos e três eletrônicos), identifica-se o tipo de acesso e as orientações do discurso das notas publicadas. Argumenta-se que os meios de comunicação locais em Veracruz construíram um discurso que deu maior espaço aos atores do contramovimento que se opunham aos direitos sexuais e reprodutivos, com uma tendência a publicar notas orientadas a uma apresentação de apreciações, posicionamentos e ideias negativas sobre o aborto. Os resultados se apresentam como uma contribuição analítica para o estudo das mediações que estabelecem os meios de comunicação nos conflitos por direitos na esfera subnacional no México, ao mesmo tempo que levanta questões a respeito das mudanças que podem ocorrer após a despenalização do aborto em Veracruz em 2021.
Keywords:

Abortion, Media

Discourse, Mediations, Movementcountermovement.

Palavras-chave: aborto, discurso midiático, mediações, movimentos-contramovimentos. 


\section{Introducción}

El derecho de las mujeres a decidir sobre su propio cuerpo, materializado, entre otras, en la posibilidad de acceder de manera legal al aborto, es uno de los principales campos de disputa política y sociocultural a lo largo y ancho del continente latinoamericano (Bergallo et al., 2018). La movilización a favor de los derechos sexuales y reproductivos en general, y de la despenalización del aborto en particular, se ha dinamizado en la última década en todo el continente tras la irrupción de "la marea verde" en Argentina y sus diferentes manifestaciones regionales (Bergallo et al., 2018; Felitti y Ramírez, 2020). De la misma manera, los movimientos y agrupaciones contrarias a los derechos, con claros anclajes religiosos y conservadores, han renovado sus estrategias de movilización con identificaciones como la "ola celeste", retomando el discurso "provida" y en oposición a lo que denominan "ideología de género" (Biroli y Caminotti, 2020; Lemaitre, 2013; Morán, 2018; Pérez Bentancur y Rocha-Carpiuc, 2020; Sáez y Morán, 2016).

En México, tras la histórica despenalización del aborto en Ciudad de México en 2007, se intensificaron en todos los estados las demandas de las organizaciones feministas por el reconocimiento de sus derechos, así como la presencia de grupos, organizaciones y movimientos conservadores que los han limitado o bloqueado (Amuchástegui et al., 2010; Beer, 2021; Fernández, 2020; Hernández, 2019; Zaremberg y Guzmán, 2019). Dentro de esta trayectoria, el año 2021 fue uno de quiebre. Por un lado, a la histórica despenalización de la Ciudad de México se sumaron Oaxaca (2020), Veracruz e Hidalgo (2021) con reformas legislativas estatales que despenalizaron el aborto hasta la semana 12 de gestación. Por otro lado, en septiembre de dicho año la Suprema Corte de Justicia de la Nación (SCJN) declaró inconstitucional la penalización del aborto en el Código Penal del Estado de Coahuila, abriendo con esto un precedente constitucional que deberá ser obligatorio en todos los estados del país cuando se demande por vía judicial los códigos penales estatales en la materia.

Este heterogéneo avance subnacional en materia de derechos se debe, entre otras, a las resistencias, vetos y conflictos impulsados a nivel local y estatal contra las demandas feministas (Beer, 2021). Dentro de estas dinámicas, las organizaciones feministas han exigido la despenalización total del aborto argumentando que su prohibición no 
solo es una afrenta al derecho de las mujeres a decidir sobre su propio cuerpo, sino también un grave problema de salud pública (Álvarez Enríquez, 2020; Espinosa y Jaiven, 2011; Lamas, 2017). Por su parte, los grupos y movimientos conservadores argumentan que la despenalización del aborto es contraria a la protección de la vida (Bárcenas, 2018; López, 2020). Como plantea Elizabeth Maier (2010; 2015), estas contraposiciones evidencian posturas y disputas políticas y socioculturales por los significados en torno al aborto, la vida y la reproducción, que delimitan también formas de ver las relaciones entre el Estado y los derechos reproductivos, al tiempo que ponen a prueba la configuración del Estado laico (Hernández, 2019). Paradójicamente, uno de los elementos menos estudiados en estas dinámicas en México son sus escenificaciones a nivel estatal (subnacional), así como las lógicas de mediación que permiten que los discursos de los movimientos y contramovimientos circulen en la esfera pública y mediática.

Teniendo en cuenta el rol que cumplen los medios de comunicación en la configuración del poder simbólico (Castells, 2009; Martín Barbero, 1987; Thompson, 1998; Van Dijk, 2009), en cuanto delimitan un espectro muy importante de la construcción del discurso público "legítimo" (Bourdieu, 1997; Hall, 2010; Van Dijk, 2009), y que las políticas de aceptación o rechazo de este tipo de derechos controvertidos suelen ir de la mano de ideas preconcebidas en la esfera pública (sobre derechos y prejuicios, entre otras), es pertinente preguntarse por las lógicas de poder con las que los medios construyen el discurso noticioso en torno al aborto. En tal sentido, si bien asistimos a una coyuntura de efervescencia global de la movilización feminista y el uso de las redes sociodigitales para la difusión de sus demandas (Álvarez Enríquez, 2020; Bárcenas, 2020; Cerva, 2020; Felitti y Ramírez, 2020; Rovira, 2018), como lo recuerda la socióloga Deana Rohlinger (2015) las disputas por el derecho al acceso legal al aborto continúan encontrando en los medios de comunicación tradicionales (como la prensa) un espacio de mediación y difusión de marcos de representación que orientan muchas de las discusiones públicas, especialmente las de las esferas políticas de toma de decisiones.

Para abordar el problema de la mediación que establecen los medios en las disputas de los movimientos y contramovimientos por los derechos sexuales y reproductivos a nivel subnacional en México, en 
este artículo estudio el caso de Veracruz, estado donde confluyen diferentes fenómenos que resaltan la centralidad de las disputas a favor y en contra de la despenalización del aborto. Por una parte, la presencia histórica del veto conservador frente a los derechos sexuales y reproductivos - destacando que en 2016 el gobierno estatal aprobó una cláusula de protección de la vida desde la concepción que en la práctica se estableció como un bloqueo contra la posibilidad de despenalizar el aborto-, al tiempo que existe una activa presencia de organizaciones movilizadas contra los derechos sexuales y reproductivos en el estado (López, 2020). Por otra parte, una importante presencia del movimiento feminista que logró avanzar hasta la aprobación legislativa del aborto en julio del 2021, luego de una intensa movilización por los derechos sexuales y reproductivos que se caracterizó por la creación de coaliciones con presencia local y nacional. En el proceso hasta la despenalización, el movimiento feminista del estado impulsó, entre otras, la primera estrategia de litigio que activó una Alerta de Violencia de Género por Agravio Comparado relacionada con el aborto en el país, la cual si bien no fue acatada por el poder legislativo estatal sí llegó hasta la Suprema Corte de Justicia de la Nación (Estrada Bautista, 2021).

Para analizar la construcción del discurso mediático en torno al aborto en Veracruz sigo las herramientas teórico-metodológicas brindadas por Van Dijk (2009; 2016), haciendo énfasis en el tipo de acceso al discurso mediático y la orientación de la estructura de las noticias como indicadores fundamentales de las lógicas de poder que los medios construyen en torno al aborto. Dado que los medios de información de noticias tienen el objetivo de influir en la discusión pública y las élites, estos indicadores evidencian el tipo de mediación que establecen los medios dentro de las dinámicas de movilización y contramovilización por los derechos sexuales y reproductivos. Para ello sistematizo y analizo todas las notas publicadas y difundidas en plataformas sociodigitales por seis medios locales durante 2019 (tres impresos y tres electrónicos) cuyo tema central era el aborto. El trabajo de campo y análisis fue realizado para el año 2019, posteriormente a que el Congreso estatal se negara a fallar de acuerdo con la Alerta de Violencia de Género y remitiera el caso ante la Suprema Corte de Justicia de la Nación, y dos años antes de la despenalización por la vía legislativa. 
El argumento principal es que el estudio del discurso mediático respecto del aborto permite entender las dinámicas de mediación que se generan en el conflicto movimiento-contramovimiento por los derechos sexuales y reproductivos, destacando en el caso de Veracruz que los medios de comunicación, con algunas variantes internas, establecieron una tendencia de mediación favorable a las posiciones de quienes se oponían a la despenalización, dando mayor acceso al discurso noticioso a actores del contramovimiento, generando orientaciones en las que tendieron a prevalecer valoraciones negativas sobre el aborto. Este análisis pretende ser una propuesta replicable a otros momentos y contextos para estudiar los discursos mediáticos que se producen en torno al aborto en México a nivel subnacional.

\section{El discurso mediático y la mediación movimiento- contramovimiento: bases teórico-metodológicas}

Desde sus orígenes, la relación entre movimientos sociales y medios de comunicación masiva ha sido central (Cammaerts, 2019; Tarrow, 2004; Tilly y Wood, 2010). Para los movimientos sociales los medios de comunicación pueden ayudar a brindar legitimidad o visibilidad a sus causas, abriendo la posibilidad de hacer circular temas acerca de los que se dirigen sus demandas y que de otra forma no entrarían dentro de las agendas de discusión pública, dadas las resistencias de actores poderosos. Al mismo tiempo, los medios de comunicación también pueden ser espacios para estereotipar o estigmatizar los movimientos, restringiendo sus oportunidades de visibilidad. En otras palabras, los medios deciden qué actores estarán representados públicamente, qué se dirá de ellos y cómo se dirá (Cammaerts, 2012; Silverstone, 2005; Van Dijk, 2009).

Estas relaciones implican una dinámica de mediación en tanto esta se define como "un proceso social en el que los medios de comunicación soportan el flujo de discursos, significados e interpretaciones en las sociedades" (Mattoni y Treré, 2014, p. 260). Como recuerda Jesús Martín Barbero, la mediación está estrechamente relacionada con los sentidos y los vínculos de interpretación y experiencia no directa de los fenómenos y los procesos, atravesados por las relaciones y estructuras de poderresistencia en que se inscriben (Martín Barbero, 1987), es decir, la forma como la comunicación a través de tecnologías (medios) permite la circulación de significados y experiencias (Couldry y Hepp, 2016). 
En este sentido, los medios de comunicación son fundamentales ya que cumplen el papel de mediación de marcos interpretativos que ayudan a configurar, justamente, una opinión pública acerca de la deseabilidad o no de temas relevantes (Cammaerts, 2012; Ferree, 2002; Rohlinger, 2015). La importancia de los medios de comunicación para la construcción, influencia, modelación y orientación de la "opinión pública" se fundamenta en el poder simbólico que ejercen, entre otras, a través de la producción y circulación de las noticias (Bourdieu, 1997; Castells, 2009). El ejercicio de dicho poder genera efectos cognitivos a través de acciones como nombrar, definir, avalar y persuadir en la presentación de un tema, mecanismo mediante el cual las personas construyen ideas (con efectos de verdad) de una realidad a la que no tienen (generalmente) acceso físico (Castells, 2009; Thompson, 1998; Van Dijk, 2009).

Si entendemos que el poder simbólico de los medios se refleja en la capacidad de delinear y controlar agendas en torno a temas públicos, debemos seguir la recomendación de Van Dijk de preguntarnos quiénes tienen acceso al recurso fundamental de poder que es el discurso público y el discurso de los medios como uno de sus constitutivos, ya que "el poder está relacionado con el control y el control del discurso implica un acceso preferencial a su producción y, por consiguiente, a sus contenidos y su estilo y, por último, a lo que piensa el público" (Van Dijk, 2009, p. 13). De esta manera se identifican las representaciones cognitivas de grupos, socialmente compartidas, actitudes e ideas que están en la base de la práctica y que se legitiman a través del discurso mediático (Van Dijk, 2016).

La cobertura y orientación de los medios en torno a temas clave de los cuales los movimientos y contramovimientos tienen intereses delineados por sus repertorios y objetivos se vuelve un indicador claro de la mediación que se establece. En el caso de las discusiones en torno al aborto la medicación se puede identificar en el tipo de cobertura que los medios realizan del tema, haciendo énfasis en el acceso al discurso y las orientaciones que lo configuran (Van Dijk, 2009).

\section{Metodología}

Para lograr el objetivo planteado seleccioné el corpus empírico de la investigación, partiendo de las características especiales de la circu- 
lación del discurso mediático en el estado de Veracruz. Por un lado, según el Padrón Nacional de Medios Impresos, Veracruz es el estado que cuenta con más periódicos impresos de todo México, con un total de 32, a pesar de los bajos indicadores de lectores. Esta característica refleja la dinámica política clientelar en la que se inscribe el sector en el estado, donde los periódicos tienen una importancia especial pues suelen ser utilizados por actores políticos para promover sus agendas o como medio de golpeteo político (Del Palacio, 2015). Por otro lado, según los datos de la Encuesta Nacional de Consumo de Contenidos Audiovisuales del 2018, realizada por el Instituto Federal de Telecomunicaciones, IFT, del 85\% de personas que dicen seguir noticias en México, el $42 \%$ lo hace a través de televisión abierta y el $22 \%$ lo hace a través de las redes sociales; de estos últimos el $85 \%$ dice seguir noticias a través de Facebook (IFT, 2019). En Veracruz los datos son consistentes a la media nacional, pues el $89 \%$ de las personas dice seguir noticias, y del $52 \%$ de la población que utiliza redes sociales el $29 \%$ consulta habitualmente las noticias en dichas plataformas (IFT, 2019).

Una vez definida la centralidad de las redes sociales en el consumo de noticias y, al mismo tiempo, el rol político que sigue teniendo la prensa tradicional en la orientación de las discusiones de las élites locales, seleccioné tres medios impresos y tres electrónicos que tienen presencia y circulación en las redes sociodigitales ${ }^{1}$. Para la selección de los medios procedí de la siguiente manera: para los medios electrónicos identifiqué los tres con mayor número de seguidores en su perfil de Facebook como principal indicador disponible a la hora de valorar su alcance: XEU Noticias, Alcalorpolitico, Noreste.Net; para los medios impresos valoré el número de tirajes diarios promedio según el Padrón Nacional de Medios Impresos (ya que este indicador permite aproximarse al nivel de difusión que busca el periódico a nivel estatal) y lo crucé con el nivel de seguidores en el perfil de Facebook (ubicando que se encontraran dentro de los diez primeros): El Mundo de Córdoba-Orizaba (27.350 tirajes promedio), El Diario de Xalapa (51.688 tirajes promedio) y El Dictamen (29.500 tirajes promedio) (Ver Figuras 1 y 2).

1 Decidí analizar el contenido que circula en Facebook, porque es la red sociodigital más utilizada en México. Según el IFT (2018): el 90\% de las personas que tienen acceso a internet en México utiliza Facebook. 
Figura 1

Total de seguidores del perfil de Facebook de diarios impresos en Veracruz y tirajes reportados al PNMI (enero 2020)

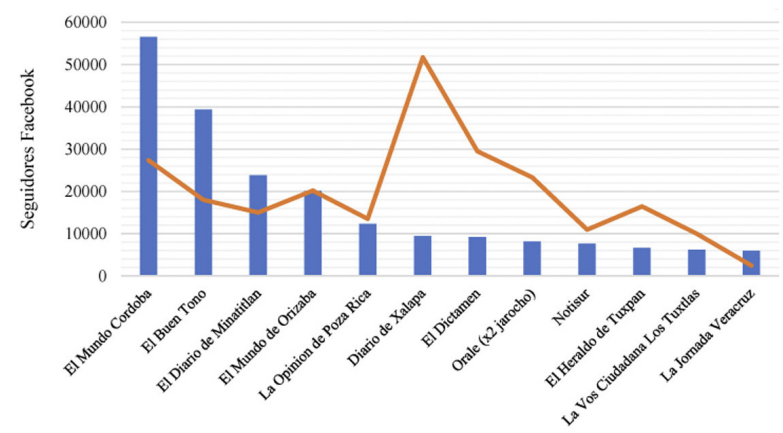

Figura 2

Total de seguidores en perfil de Facebook de principales plataformas digitales de noticias en Veracruz (enero 2020)

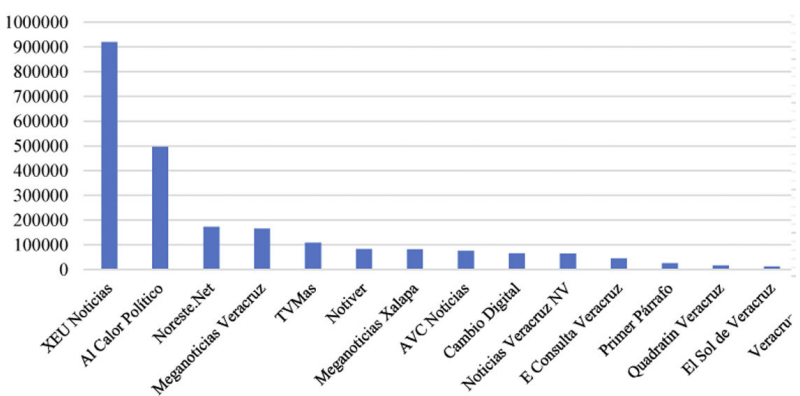

Fuente: Elaboración propia con información de los perfiles de Facebook y de Padrón Nacional de Medios Impresos.

Una vez identificados los medios, procedí a la sistematización de las noticias. Para ello ubiqué a través del buscador con filtros personalizados de Facebook todas las notas publicadas que contuvieran en su titular o encabezado la palabra "aborto" durante el 2019. Esta selección se basó en la premisa según la cual los titulares y encabezados de las notas marcan el eje principal del contenido de la producción de la información $\mathrm{y}$, dada la estructura de la red, el principal mensaje que consumen los receptores; definí la búsqueda por la palabra "aborto" ya que es el significante generalizado utilizado para referirse a la interrupción del embarazo y sobre el que gira la mayor parte de la discusión pública. 
Tabla 1

Total de notas seleccionadas para el estudio

\begin{tabular}{lc}
\hline Medio & Notas \\
\hline El Dictamen & 41 \\
\hline El Diario de Xalapa & 57 \\
\hline El Mundo & 39 \\
\hline Noreste.Net & 36 \\
\hline Alcalorpolitico & 38 \\
\hline XEU Noticias & 46 \\
\hline Total & 257 \\
\hline
\end{tabular}

Fuente: Elaboración propia.

En total, durante todo 2019 trabajé con 257 publicaciones que cumplían estas características, las cuales se distribuían como se observa en la Tabla 1. En promedio, se publicaron 40 notas electrónicas y 45 impresas que abordaron el tema del aborto de manera explícita y central. Luego de esto, el total de notas fue clasificado a partir de las categorías y dimensiones del análisis crítico del discurso mediático.

\section{Las disputas por la despenalización del aborto en Veracruz: contexto y actores}

El movimiento feminista en México ha puesto en el centro de sus reclamos el reconocimiento de los derechos sexuales y reproductivos como la forma en que las mujeres pueden ejercer autonomía sobre sus cuerpos, exigido el acceso al aborto legal y seguro como alternativa de decisión sobre sus trayectorias vitales (Espinosa y Jaiven, 2011; Felitti y Ramírez, 2020; Lamas, 2017; Maier, 2015). Para el caso de Veracruz el movimiento feminista ha tenido una trayectoria de movilización, articulación e incidencia política que ha permitido la acción colectiva para el impulso de los derechos de las mujeres. Como recuerda Estrada (en una de las pocas reconstrucciones históricas que se tienen del movimiento en el estado), en Veracruz ha existido una constante articulación de acción colectiva feminista, especialmente a través de organizaciones de la sociedad civil, que ha impulsado agendas de defensa de derechos ante problemas tan importantes como la violencia de género, la participación política y los derechos sexuales y reproductivos (Estrada Bautista, 2021). 
Esta movilización se ha visto representada con la creación de asociaciones civiles, desde organizaciones creadas en los años 80 y 90 como el Colectivo Feminista de Xalapa y el Colectivo Feminista Cihuatlahtolli, hasta un conjunto de organizaciones y colectivas creadas en el siglo XXI que articulan la acción colectiva de diversas mujeres como Kalli Luz Marina de Orientación y Promoción de las Mujeres A.C., Agrupación de Derechos Humanos Xochitéptl, Salud y Género A.C., Xochiquetzal Centro de Estudios Sociales A.C., Equifonía. Colectivo por la Ciudadanía, Autonomía y Libertad de las Mujeres A.C., Colectivo de Investigación y Desarrollo entre Mujeres A.C., Colectivo Akelarre, entre otras (Estrada Bautista, 2021). Estas organizaciones y sus alianzas de presión gubernamental han permitido la creación de leyes tan importantes como la Ley de Acceso de las Mujeres a una Vida Libre de Violencia en el 2008, la Ley de Igualdad entre Hombres y Mujeres del 2009 y la tipificación del feminicidio en 2011. Como producto de estas trayectorias de movilización en julio de 2021 fue despenalizado el aborto en Veracruz por la vía legislativa. Sin embargo, el camino de las luchas y conflictos para lograr dicho reconocimiento fue largo y sinuoso.

Para empezar, en Veracruz se ha mantenido una histórica presencia de organizaciones y grupos conservadores con capacidad de veto e incidencia política. Es así como, por ejemplo, en 2008 el propio gobernador del estado, Fidel Herrera (2004-2010), envió una iniciativa al Congreso de la Unión proponiendo dar marcha atrás a la despenalización del aborto lograda en el Distrito Federal en 2007, sumándose a la ola de respuestas conservadoras que se generaron en todo el país (Hernández, 2019). Esto fue posible dada la importante presencia pública de la Iglesia católica, particularmente a través de la arquidiócesis de Xalapa y su gran influencia en las subregiones como Coatzacoalcos, Córdoba y Orizaba. Entre los actores políticos que históricamente han tenido una posición contraria a los derechos sexuales y reproductivos se encuentran el Partido Acción Nacional (PAN), el Partido Revolucionario Institucional (PRI) y, tras su reciente creación, el evangélico Partido Encuentro Social.

Como articulación formal de estas resistencias a través de estrategias de organización y contramovilización, en 2016 se crearon los nodos estatales del Frente Nacional por la Familia en Xalapa, Veracruz, 
Córdoba y Coatzacoalcos ${ }^{2}$. Igualmente tiene importante presencia estatal el Consejo Veracruzano Más Vida Más Familia (previamente denominada Vida Familia), liderada desde Coatzacoalcos y que en 2016 promovió exitosamente la reforma al Código Civil que definió la protección de la vida desde la concepción. Estas organizaciones tienen claros vínculos con la jerarquía de la Iglesia católica ${ }^{3}$, pertenecen a redes internacionales como la Coalición Sumas y mantienen una importante presencia en los medios.

Frente a estas históricas resistencias, una de las varias respuestas de las organizaciones feministas fue la conformación en 2009 de

la Articulación Estatal por el Derecho a Decidir (...) Entre las organizaciones que conformaron la articulación, se encontraban: Xochiquetzal A.C; Equifonía; Colectivo de Investigación, Desarrollo y Educación entre Mujeres (CIDEM) A.C; Haceres A.C; Colectivo Feminista de Xalapa A.C y la Red de Mujeres Comunicadoras "Las Muchas". (Estrada Bautista, 2021, p. 109)

Luego de los fallidos primeros intentos de reforma, como ya mencionamos, en 2015 la organización conservadora "Sí Vida" promovió una reforma de ley para proteger la vida desde la concepción, organizando marchas y plantones en diversas ciudades del estado. Nuevamente como respuesta a la propuesta de reforma impulsada por grupos conservadores, las organizaciones del movimiento feminista crearon la Red Veracruzana por el Derecho a Decidir (RVDD) integrada por Salud y Género A.C; Piensa, Actúa y Sorprende A.C; Colectivo Akelarre A.C; Colectivo Feminista de Xalapa, A.C; Buscando a Nuestras Hijas; Movimiento Amplio de Veracruz y de Boca del Río (MAMBVER); Frente Popular de Mujeres; ECOSEX, A.C; Hagamos Algo, A.C; Abogadas con Perspectiva, A.C; Aura, A.C; MEXFAM, capítulo Veracruz; Redefine, Veracruz y Católicas por el Derecho a Decidir Veracruz. Esta red tuvo como objetivos:

2 Sobre el Frente Nacional por la Familia y las organizaciones civiles que se han articulado para oponerse a los derechos sexuales y reproductivos en México, ver Bárcenas (2018); López (2018; 2020).

3 Si bien en el estado también existe presencia de iglesias pentecostales y neopentecostales, los vínculos de las organizaciones civiles y políticas son claramente más visibles y estrechos con la Iglesia católica. Sobre la presencia de estas otras iglesias, ver Vázquez (2007). 
1) frenar la reforma al Art. $4^{\circ}$ Constitucional y cualquier iniciativa que intentara criminalizar el derecho a decidir; 2) vigilar el cumplimiento de la NOM 046 y las políticas públicas que atañen a los derechos sexuales y reproductivos de las mujeres; y 3) incidir en la opinión pública y política respecto a la despenalización del aborto. (Estrada Bautista, 2021, pp. 111-112)

A pesar de estas respuestas, en 2016 el gobierno estatal a la cabeza del entonces gobernador Javier Duarte (2010-2016) promulgó la modificación del artículo 4 constitucional para "proteger la vida desde la concepción hasta la muerte", lo que contradijo y obstaculizó el acceso al aborto bajo las causales referidas, y puso mayores restricciones a la posibilidad de que el movimiento feminista lograra la despenalización total del aborto en el estado.

Frente a esta continuidad, en abril de 2016 las organizaciones Equifonía, Haceres, Xochiquetzal, Colectivo Akelarre, Caminos del Buen Vivir, Centro Las Libres, Observatorio Nacional del Feminicidio y el Comité Promotor por una Maternidad Segura, entre otras, presentaron una solicitud de Alerta de Violencia de Género contra las Mujeres por Agravio Comparado. Esta acción representó un novedoso litigio estratégico buscando obligar al Congreso del Estado a legislar para despenalizar el aborto. Como resultado de sus acciones, en diciembre de 2017, ya bajo la gubernatura del panista Miguel Ángel Yunes (20162018), la Comisión Nacional para Erradicar la Violencia Contra las Mujeres emitió una Alerta de Género bajo la figura de Agravio Comparado para el estado de Veracruz, única de su estilo en el país, la cual señaló que en Veracruz se manifestaba violencia institucional contra las mujeres al prohibir el aborto y la actitud omisa y de negación del estado y las instituciones públicas de realizarlo bajo las causales específicas.

Esta Alerta de Género obligaba a los legisladores a realizar modificaciones en el Código Penal para despenalizar el aborto ${ }^{4}$, y dado que estas

4 La cual señaló que en el estado se presenta una constante violencia institucional al prohibir el aborto y la actitud omisa y de negación del estado y las instituciones públicas de realizarlo bajo las causales específicas. Dentro de las recomendaciones realizadas por esta segunda alerta de género por agravio comparado, única de su estilo hasta el día de hoy en México, se encuentra: 1) estudiar, revisar y armonizar los artículos 149, 150 y 154 del Código Penal para el estado de Veracruz, reformulando el delito del aborto para que ese sea considerado hasta las 12 semanas de gestación; 2) eliminar el límite de 90 días para la causal de violación; 3 ) establecer como causal de aborto la salud de la madre; 
no se realizaron, el 2 de julio de 2018 el juez décimo octavo de Distrito concedió dos amparos que indicaban que existía una flagrante omisión legislativa que violentaba los derechos humanos de las mujeres a la protección de su dignidad, no discriminación, libertad y salud sexual y reproductiva. Los amparos obligaban a los legisladores estatales a realizar las modificaciones antes del 31 de julio del 2018, día en que vencía el periodo ordinario. Como respuesta, el Frente Nacional por la Familia y los partidos políticos como el PAN, el PRI y el PES, impulsaron una fuerte oposición legislativa y mediática, logrando que el Congreso del Estado no respondiera a la medida y enviara el asunto a la Suprema Corte de Justicia de la Nación (López, 2020). Al no ser acatada esta medida, el caso de Veracruz llegó a la Suprema Corte de Justicia de la Nación, misma que aceptó analizarlo a mediados del año 2019.

En un contexto de falta de pronunciamiento por parte de la SCJN, en julio de 2021 el aborto fue despenalizado hasta la semana 12 de gestación tras una propuesta de reforma legislativa estatal impulsada por la diputada feminista Mónica Robles, del partido oficialista Morena, luego de diversos intentos infructuosos.

Justamente en el contexto y la coyuntura escenificada en 2019 luego de la negativa del poder legislativo a despenalizar el aborto se inscribe el análisis del discurso mediático sobre el aborto en Veracruz y la mediación que establecieron los medios en el conflicto entre el movimiento y contramovimiento frente a los derechos sexuales y reproductivos.

\section{La cobertura mediática sobre el aborto en 2019: accesos y orientaciones}

El primer elemento que permite identificar la relación de mediación que cumplen los medios dentro del conflicto por los derechos sexuales y reproductivos, se encuentra al observar la tendencia temporal de producción de las noticias que se refieren abiertamente al tema del aborto. Como se aprecia en la Figura 3, la publicación de las notas tiene los picos más altos en los meses de marzo y septiembre (concentrando en estos dos meses el $41 \%$ del total), seguidos por los meses de mayo

4) eliminar cualquier tipo de pena punitiva frente al aborto; 5) establecer excepciones como excluyente de responsabilidad; 6) reglamentar la interrupción voluntaria del embarazo hasta las 12 semanas. 
y octubre. La tendencia temporal de producción de noticias sobre el aborto evidencia una clara influencia de los repertorios del movimiento y el contramovimiento, pues durante estos cuatro meses se conmemoran activamente fechas de reivindicación simbólica e institucional para ambos grupos de actores.

Figura 3

Total de notas publicadas durante el 2019 relacionadas con el "aborto" en los seis medios seleccionados

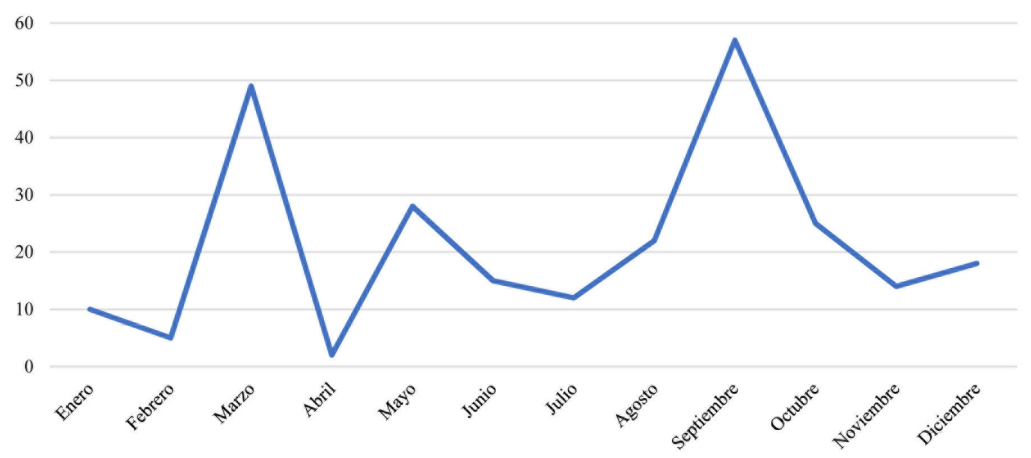

Fuente: Elaboración propia.

Por una parte, la creciente cobertura noticiosa de temas relacionados con el aborto se presenta en meses donde se dan las principales conmemoraciones y reivindicaciones instituidas por el movimiento feminista a nivel mundial. Durante el mes de marzo se presenta la conmemoración del Día Internacional de la Mujer Trabajadora, que ha tenido una creciente visibilidad global con las apropiaciones de tecnologías de comunicación digital y multitudinarias marchas en las sociedades occidentales convocadas con los hasthags \#8M \#NiUnaMejos \#NuncaMasSinNosotras, entre otras (Requena, 2019; Rovira, 2018). El 28 de mayo se conmemora, como resultado del V Encuentro Internacional de Salud de las Mujeres en Costa Rica, el Día Internacional de Acción por la Salud de las Mujeres, en el cual la demanda por el aborto legal es central, dado su claro vínculo como un asunto de salud pública. Finalmente, desde el año 1990, tras el V Encuentro Feminista Latinoamericano y del Caribe, se conmemora el 28 de septiembre el Día de Acción Global por el Acceso al Aborto Legal y Seguro. 
Por otro lado, además de los repertorios instituidos de conmemoración de fechas que reivindican el reconocimiento de los derechos de las mujeres, una acción estratégica de los contramovimientos ha sido establecer repertorios de protesta que se circunscriben a momentos simbólicos que construyen marcos opositores a los feministas. Así, el 25 de marzo las organizaciones conservadoras de todo el mundo, respaldadas por las jerarquías de la Iglesia católica, conmemoran "El día del niño por nacer". Además, desde el año 2016 en México el contramovimiento articulado de manera coordinada en el Frente Nacional por la Familia y la Unión de Padres de Familia, con el protagonismo de diversas iglesias, ha impulsado manifestaciones callejeras para oponerse a los derechos sexuales y reproductivos semanas antes del día de acción global por el aborto seguro. Específicamente, para el 2019 las dos principales marchas nacionales convocadas bajo los marcos de "Defensa de la vida" y "A favor de las dos vidas" se dieron el 21 de septiembre y el 26 de octubre.

Estos resultados confirman la tesis de la mediación e influencia que se establece entre las acciones de protesta de los movimientoscontramovimientos, los medios y los procesos de comunicación (Cammaerts, 2012), pues aparece una correlación entre la presencia de las reivindicaciones públicas e instituidas a favor o en contra del aborto con un mayor interés de producción de información sobre este tema por parte de los medios.

Figura 4

Lugar de referencia de las notas publicadas durante el 2019 relacionadas con el aborto en los seis medios seleccionados

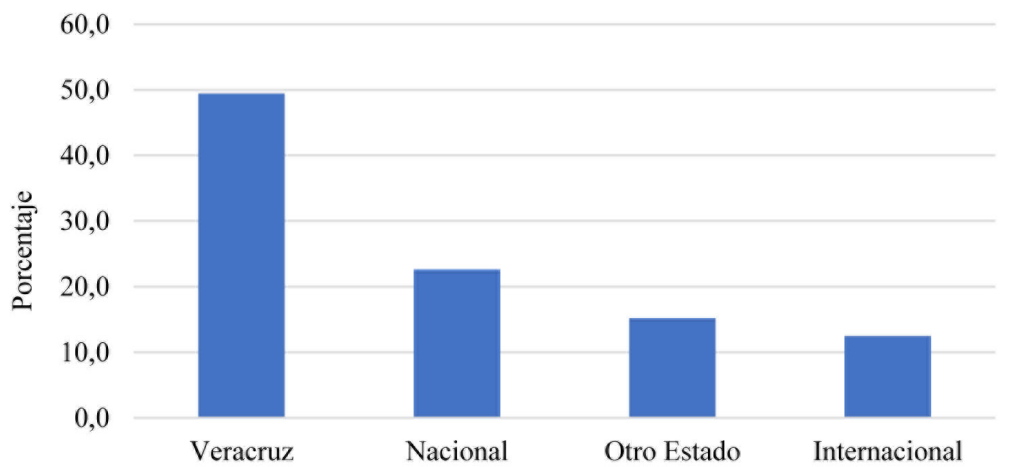

Fuente: Elaboración propia. 
Como se observa en la Figura 4, la lógica de la mediación no se limita al ámbito estatal, aunque este es mayoritario en la cobertura, sino que también existe resonancia de las realidades nacionales e internacionales en la generación de noticias respecto del aborto. Ahora bien, la mediación e influencia establecida de las disputas por los derechos sexuales y reproductivos no implica, necesariamente, la producción de un discurso mediático neutral o equilibrado, como veremos a continuación.

\section{El acceso al discurso mediático y la prevalencia del contramovimiento}

Retomando la tesis de Van Dijk (2009) en cuanto al acceso al discurso mediático como un elemento fundamental de la construcción y reproducción de relaciones de poder, se identifica qué tipo de actores e intereses tienen voz autorizada para referirse al aborto en los medios locales.

Como se observa en la Figura 5, en el $34 \%$ de las notas el actor que es citado y referido en el titular y encabezado hace parte del contramovimiento, en contraste con tan solo el $19 \%$ de los casos en donde la voz autorizada o referencia establecida para abordar una nota relacionada con el aborto es un actor que se identifica directamente con el movimiento. De los restantes, en un $29 \%$ de los casos se cita a otro tipo de actores o no se hacen referencias, mientras que en un $18 \%$ se refiere a actores políticos que no tienen una identificación directa con ninguna de las partes (por lo general se refieren a testimonios de coordinadores de bancadas del congreso local, o del gobierno federal, haciendo alusión a posibles trámites legislativos). 
Figura 5

Tipo de actor citado en el titular y encabezado de las notas relacionadas con el aborto durante 2019 en los seis medios seleccionados

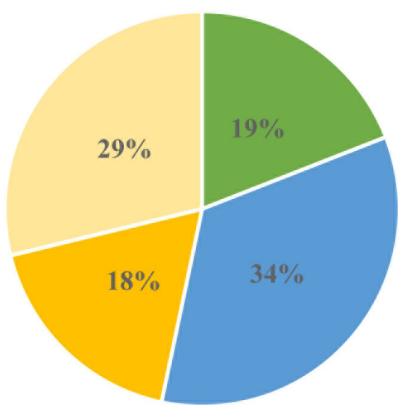

- Movimiento $=$ ContraMovimiento $=$ Político/a sin identificación directa de activismo $=$ Otros actores

Fuente: Elaboración propia.

Si bien el acceso al discurso mediático tiene una preponderancia de los actores del contramovimiento, esto no es igual en términos proporcionales en todos los medios estudiados. Es importante identificar diferencias en las líneas de producción noticiosa que evidencian con claridad la tendencia ideológica y política de cada medio. En este sentido, resalto que los medios que más acceso dieron a los actores del movimiento a favor de los derechos sexuales y reproductivos fueron $\mathrm{Al}$ calorpolitico y El Mundo, con un 34,2\% y 28,2\% respectivamente; no obstante, es de resaltar también que exactamente esa misma proporción de acceso se presentó para los actores del contramovimiento en cada caso.

Tabla 2

Porcentaje de actores citados en los titulares y encabezados de las notas publicadas durante 2019 relacionadas con el aborto

\begin{tabular}{lccc}
\hline \multirow{2}{*}{ Medio } & \multicolumn{3}{c}{ Acceso al discurso mediático } \\
\cline { 2 - 4 } & Movimiento \% & Contramovimiento \% & Otro \% \\
\hline El Dictamen & 17,1 & $\mathbf{3 4 , 1}$ & 48,8 \\
\hline El Diario de Xalapa & 19,3 & $\mathbf{4 7 , 4}$ & 33,3 \\
\hline El Mundo & $\mathbf{2 8 , 2}$ & $\mathbf{2 8 , 2}$ & 43,6 \\
\hline Alcalorpolitico & $\mathbf{3 4 , 2}$ & $\mathbf{3 4 , 2}$ & 31,6 \\
\hline XEU Noticias & 8,7 & $\mathbf{3 9 , 1}$ & 52,2 \\
\hline Noreste.Net & 8,3 & $\mathbf{1 3 , 9}$ & 77,8 \\
\hline
\end{tabular}

Fuente: Elaboración propia. 
Por su parte, y con una tendencia totalmente opuesta, El Diario de Xalapa con el 47,4\% y XEU Noticias con el 39,1\% de sus notas encabezadas con citas y referencias a actores del contramovimiento, tuvieron una clara línea editorial que le dio voz a la Iglesia católica, siendo en cada caso el diario impreso con más tirajes y el medio electrónico con más seguidores en redes sociodigitales, así como los medios con más notas publicadas (como lo presentamos en el apartado metodológico). Este resultado es muy revelador, pues el papel jugado por ambos medios en términos comparados (con un perfil claramente alineado con las ideas de la Iglesia católica y valores conservadores), indica la gran importancia que tiene para estos representantes del contramovimiento el posicionamiento en el discurso público mediático de sus posturas frente al aborto.

Del total de notas que dan acceso privilegiado al discurso a los actores del contramovimiento, un $51 \%$ cita a la Iglesia católica y sus altos jerarcas como la voz autorizada para abordar el tema relacionado con el aborto, seguido del $24 \%$ de notas que referencian a organizaciones líderes del contramovimiento como el Frente Nacional por la Familia, y un $14,8 \%$ de notas que dan voz a políticos o políticas que abiertamente se identifican con la agenda del contramovimiento. Esto indica claramente que la Iglesia católica juega un rol central en el acceso y direccionamiento del discurso público en torno al aborto, porcentaje que no varía si dividimos entre medios electrónicos y medios impresos.

En relación con el movimiento, un $61,2 \%$ del total de notas que citan directamente a un actor relacionado con el movimiento en sus titulares o encabezados lo hacen con identificaciones como "la marea verde", "el movimiento por el aborto", "colectivos de mujeres", entre otras. En este caso es un discurso que se relaciona directamente con el movimiento en abstracto, sin encontrar actores o agentes concretos de visibilidad institucional como portavoces autorizados en el discurso mediático (como la Iglesia católica o el FNF en el caso del contramovimiento).

Finalmente, el acceso al discurso mediático en torno al aborto reproduce también sesgos respecto del sexo de las voces autorizadas, pues se observa que en el $29 \%$ se citan hombres en los titulares y encabezados, mientras que las mujeres son citadas en el $21 \%$ de las 
notas analizadas. En este punto, el discurso mediático sobre el aborto, que tiene a las mujeres como principales interesadas, reproduce un sesgo patriarcal de autorización al ser los hombres las voces más visibles en lo individual para referirse al tema (y la Iglesia católica en lo colectivo).

\section{Orientación de las noticias: entre valoraciones y escándalo}

Como plantea Van Dijk (2016), además del acceso también es importante la orientación de los discursos mediáticos, ya que "la reproducción discursiva del poder es principalmente persuasiva. Más que prescripción directa, el discurso del poder se caracteriza por argumentar dando razones económicas, políticas, sociales o morales y administrando el control de la información importante" (Van Dijk, 2009, p. 74). En tal sentido, el tipo de estructura del discurso mediático deriva en el tipo de cobertura que se realiza del tema y las implicaciones directas en términos del poder simbólico que se reproduce a través de la narración y orientación de la realidad (Van Dijk, 2009).

Como se observa en la Figura 6, el tipo de cobertura que realizaron los medios locales en Veracruz está claramente orientado a la exposición de opiniones o tomas de posición de actores en torno al aborto, siendo un preponderante $52 \%$ de las notas de tipo "opinión o toma de posición", seguidas de un mucho menor $20 \%$ de las notas relacionadas con actos gubernamentales en relación con el aborto. Este hallazgo es muy significativo, ya que refleja una orientación mayoritaria del discurso mediático que se difundió en los medios en Veracruz hacia dar voz o visibilidad a valoraciones en torno al aborto (con prevalencia de acceso al contramovimiento). La orientación prevaleciente del discurso mediático hacia la opinión o toma de posición refleja que este es un tema abierto respecto del cual las valoraciones personales o colectivas delinean un campo de disputas por las construcciones de sentido en torno a los derechos sexuales y reproductivos. 
Figura 6

Orientación de las notas publicadas sobre el aborto durante 2019 en los seis medios seleccionados

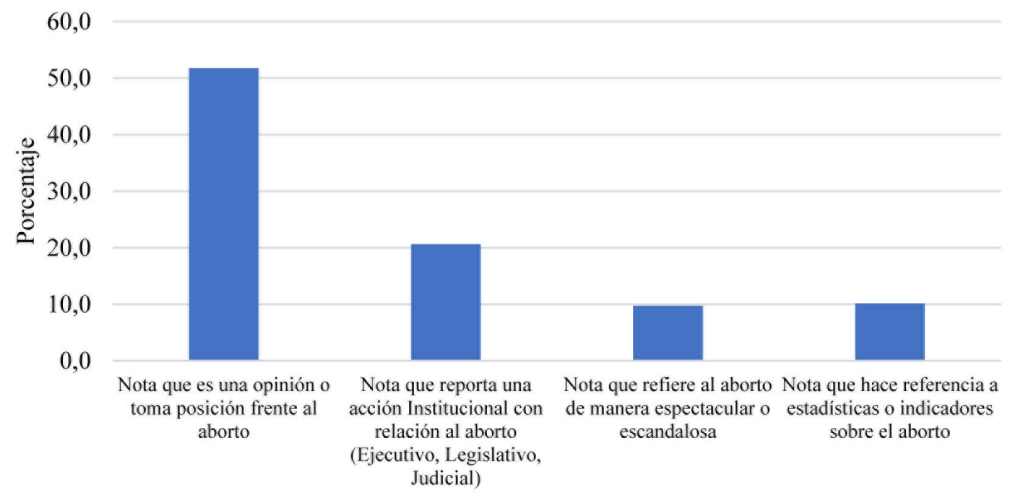

Fuente: Elaboración propia.

Igualmente destaca que cuando no se perfilan en la exposición de valoraciones $\mathrm{u}$ opiniones dentro de las orientaciones de las noticias, las notas que reportan las decisiones gubernamentales prevalecen con un $20 \%$ y tan solo un $10 \%$ presentan notas para exponer estadísticas o indicadores sobre el aborto, con el mismo valor que aquellas notas que se refieren al aborto de manera espectacular o escandalosa.

Como se observa en la Figura 7, dentro de esta estructura del discurso identificamos que el $22,3 \%$ de las notas establece un marco narrativo que orienta una representación o valoración positiva en torno al aborto (al ubicarlo como un tema de derechos, como un asunto de salud pública, como una realidad que hay que atender, entre otras), mientras que el $27,3 \%$ de las notas orientan hacia una valoración abiertamente negativa (dando argumentos de porqué debe ser un delito, no debe ser despenalizado, entre otros). Ahora bien, igualmente importante es que $21,5 \%$ de las notas tiene explícitamente un tono que escandaliza o atemoriza ante el aborto $^{5}$, y el 12,2\% lo aborda

5 Un mecanismo de producción de noticas que genera escándalo y que antes que informar desorienta en torno al debate sobre los derechos sexuales y reproductivos, tiene que ver con la publicación constante de notas donde se cita a personajes "famosos o famosas" (actrices, cantantes, entre otras), vinculándolas con casos de abortos, testimonios o problemas familiares derivados de hipotéticos abortos; titulares amarillistas como "abortó a su bebé de 7 meses", "abortó y enterró el feto", resaltando la dimensión de 
bajo un discurso que lo presenta como situaciones no deseables e "inminentes"

Figura 7

Valoraciones en torno al aborto en las notas publicadas durante 2019 en los seis medios seleccionados

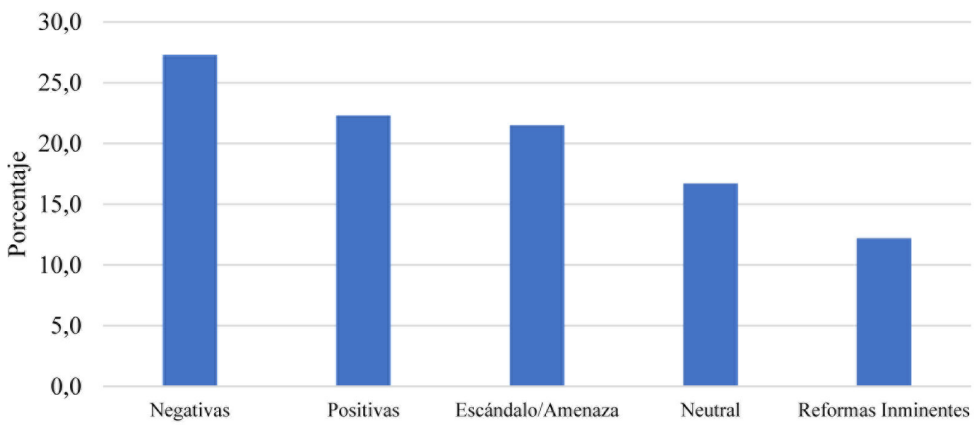

Fuente: Elaboración propia.

La prevalencia de la estructura del discurso mediático que hace énfasis en el escándalo o inminencia del aborto (como si fuera un fenómeno que se generalizaría por su despenalización), se alinea claramente con una de las estrategias centrales del contramovimiento conservador, esto es, la de promover discursos e ideas que fomentan un "pánico moral", entendido como la construcción de una idea de amenaza o ataque hacia los "valores" (morales y religiosos) de la sociedad que representan los derechos sexuales y reproductivos (Bárcenas, 2018; Careaga, 2016).

Dentro de esta tendencia general, aparecen nuevamente diferencias significativas en relación con la orientación de los discursos entre los medios seleccionados. El Diario de Xalapa (26,3\%), XEU Noticias $(30,4 \%)$ y Noreste.Net $(30,6 \%)$ son los medios que más apelan a la orientación hacia el escándalo de sus notas, en contraste con Alcalorpolitico

muerte y violencia. De manera contraria, pocas veces encontramos marcos que presenten narrativas e historias de mujeres que al poder practicar un aborto salvaron su vida, pudieron tener oportunidad de realización individual, entre otras.

6 Los mensajes que hacen énfasis en la inminencia del tema se caracterizan por ser notas, por lo general, al inicio de los periodos legislativos, que señalan que el "tema del aborto" se verá "colado" en las discusiones del congreso, o que más allá de las exigencias las bancadas políticas lo impondrán sin diálogo. 
(7,9\%), El Mundo (15,4\%) y El Dictamen (14,6\%) quienes lo hacen en una mucho menor proporción. De estos medios, Alcalorpolitico y $E l$ Mundo son los que mayor porcentaje de sus notas orientan con marcos positivos frente al aborto, con un $34,2 \%$ y $33,3 \%$ respectivamente, resultando entonces un discurso con orientaciones más equilibradas (aunque nunca con mayor orientación hacia los intereses del movimiento).

\section{Conclusiones}

El análisis del discurso mediático sobre el aborto en 2019 en Veracruz evidenció una tendencia general de los principales medios locales a favorecer una narrativa que daba mayor acceso a los actores del contramovimiento de los derechos sexuales y reproductivos, en contraposición con un menor acceso al movimiento, difundiendo notas que se orientaban principalmente a presentar opiniones y tomas de posición, con mayor presencia de discursos que negaban o escandalizaban en torno al aborto. Si bien el discurso no fue homogéneo en los seis medios estudiados (con variaciones que presenté en los resultados), resaltó que en ninguno de los casos algún medio daba mayor acceso al discurso al movimiento feminista en contraposición al contramovimiento, ni se presentó una orientación mayoritaria de marcos positivos en torno al aborto. Estos resultados, ubicados en una intensa coyuntura de disputa por el derecho al aborto en Veracruz, muestran que el discurso mediático tiene efectos de mediación en el conflicto entre movimientos y contramovimientos al prevalecer accesos y orientaciones que pueden beneficiar a uno $\mathrm{u}$ otro actor involucrado en la disputa pública por los derechos.

Si bien en ninguno de los medios estudiados el discurso fue abiertamente favorable a las demandas e intereses del movimiento por los derechos sexuales y reproductivos, se encontraron diferencias en algunos ejes del discurso. Por una parte, fue clara la mediación altamente favorable a los intereses del contramovimiento por parte de El Diario de Xalapa (el medio con mayor número de tirajes diarios) y XEU Noticias (el medio con mayor número de seguidores en Facebook), los medios que más notas publicaron relacionadas con el aborto en el periodo estudiado, con claras líneas de producción de noticias que se contraponen a los derechos sexuales y reproductivos, 
y una importantísima presencia del discurso de la Iglesia católica. Lo anterior se diferenció de los casos de Alcalorpolitico y El Mundo de Córdoba-Orizaba, medios que brindaron un acceso más proporcional tanto a actores del movimiento como del contramovimiento. Igualmente, en términos de las orientaciones de los discursos, $E l$ Diario de Xalapa, XEU Noticias, Noreste.Net y El Dictamen presentaron mayores proporciones de discursos orientados al escándalo, la alarma y la negativa frente al aborto, mientras que Alcalorpolitico y $E l$ Mundo tuvieron menores proporciones de estos. Los resultados indican que la construcción del discurso mediático responde más que al formato del medio (bien sea impreso o electrónico), a la decisión de hacer énfasis positivo o negativo en la cobertura y producción de la información relacionada con el aborto.

Los trabajos que han analizado la dinámica de las demandas feministas y las reacciones conservadoras frente a los derechos sexuales y reproductivos en general, y frente a la despenalización del aborto en particular, han prestado poca atención al análisis de las mediaciones que establecen los medios de comunicación como espacios de configuración del poder y la violencia simbólica. Los resultados de esta investigación dejan en evidencia la gran capacidad de los contramovimientos para posicionar argumentos, ideas y valoraciones en el espacio mediático, teniendo un gran acceso al discurso público, fundamento de reproducción de relaciones de poder. Estos resultados también son útiles para el desarrollo de una agenda de indagación que permita comprender si las dinámicas de la mediación cambian en una coyuntura donde la despenalización del aborto fue aprobada vía legislativa o si por el contrario, se mantiene la tendencia de producción de discursos. Este ámbito de indagación es importante ya que, si bien el reconocimiento legal de los derechos es fundamental, las disputas socioculturales ayudan a entender procesos de resistencia o difícil recepción de los cambios legales e institucionales en contextos determinados. Finalmente, la dimensión subnacional del análisis permite pensar los procesos más allá de las dinámicas y lecturas centralizadas, abriendo la posibilidad del estudio comparado en los estados de México, pues es importante investigar el papel que cumplen los medios como generadores de dinámicas de información y opinión orientadas a las élites estatales. 
La histórica despenalización del aborto en Veracruz durante 2021 respondió a un intenso proceso de movilización y demanda feminista que se sobrepuso a las resistencias y vetos de actores conservadores. En este sentido, la evidencia presentada sobre una clara tendencia de un discurso mediático que brindó mayor visibilidad, presencia y legitimidad a las posturas de los contramovimientos conservadores, puede ser insumo para repensar las prácticas periodísticas y de producción de noticias. Los cambios legales acaecidos con la despenalización del aborto deben llevar a replanteamientos en las formas de producción de noticias y en los discursos que son privilegiados mediáticamente, ya que debería predominar el reconocimiento de la constitucionalidad de los derechos ya instituidos antes que las posiciones o narrativas contrarias a estos derechos (por lo menos normativamente hablando). Igualmente, el discurso mediático en torno a estas disputas continúa siendo central, dada su importancia en la socialización y difusión de los cambios legales en materia de derechos humanos.

\section{Referencias}

Álvarez Enríquez, L. (2020). El movimiento feminista en México en el siglo XXI: Juventud, radicalidad y violencia. Revista Mexicana de Ciencias Politicas y Sociales, 65(240), 147-175. https://doi. org/10.22201/fcpys.2448492xe.2020.240.76388

Amuchástegui, A., Cruz, G., Aldaz, E., y Mejía, M. C. (2010). Politics, religion and gender equality in contemporary Mexico: Women's sexuality and reproductive rights in a contested secular state. Third World Quarterly, 31(6), 989-1005. https:// doi.org/10.1080/01436597.2010.502733

Bárcenas, K. (2018). Pánico moral y de género en México y Brasil: Rituales jurídicos y sociales de la política evangélica para deshabilitar los principios de un estado laico. Religião \& Sociedade, 38(2), 85-118. https://doi.org/10.1590/010085872018v38n2cap03

Bárcenas, K. (2020). \#EleNão (Él no): tecnofeminismo interseccional en Brasil frente al ascenso del neoconservadurismo evangélico y el posfascismo. Alteridades, 30(59), 43-56. https://doi. org/10.24275/uam/izt/dcsh/alteridades/2020v30n59/ barcenas 
Beer, C. (2021). Política de género y federalismo en México. Revista SAAP, 15(2), 335-361.https://doi.org/10.46468/rsaap.15.2.A4

Bergallo, P., Jaramillo, I., y Vaggione, J. (2018). El aborto en América Latina. Estrategias jurídicas para luchar por su legalización y enfrentar las resistencias conservadoras. Siglo XXI Editores.

Biroli, F. y Caminotti, M. (2020). The conservative backlash against gender in Latin America. Politics \& Gender, 16(1), E1. https:// doi.org/10.1017/S1743923X20000045

Bourdieu, P. (1997). Sobre la televisión. Anagrama.

Cammaerts, B. (2012). Protest logics and the mediation opportunity structure. European Journal of Communication, 27(2), 117134. https://doi.org/10.1177/0267323112441007

Cammaerts, B. (2019). A genealogy of communicative affordances and activist self-mediation practices. En H. Stephansen y E. Treré (Eds.), Citizen media and practice: Currents, connections, challenges. Critical perspectives on citizen media (pp. 98112). Routledge.

Careaga, G. (2016). Moral panic and gender ideology in Latin America. Religion and Gender, 6(2), 251-255. https://doi.org/10.18352/ rg.10174

Castells, M. (2009). Comunicación y poder. Alianza.

Cerva, D. (2020). La protesta feminista en México. La misoginia en el discurso institucional y en las redes sociodigitales. Revista Mexicana de Ciencias Políticas y Sociales, 65(240), 177-205. http://dx.doi.org/10.22201/fcpys.2448492xe.2020.240.76434

Couldry, N. y Hepp, A. (2016). The mediated construction of reality. Polity.

Del Palacio, C. (2015). Pasadoy presente. 220 años de prensa veracruzana (1795-2015). Universidad Veracruzana.

Espinosa, G. y Jaiven, A. L. (2011). Un fantasma recorre el siglo luchas feministas en México 1910-2010. Universidad Autónoma de México, UAM.

Estrada Bautista, L. J. (2021). Movimiento feminista en Veracruz a través de las organizaciones de la sociedad civil: Acción colectiva en el periodo de 2007 a 2017 [Tesis de maestría no publicada]. Universidad Autónoma Metropolitana Unidad Xochimilco.

Felitti, K. y Ramírez, M. del R. (2020). Pañuelos verdes por el aborto legal: Historia, significados y circulaciones en Argentina y 
México. Encartes, 3(5), 110-145. https://encartes.mx/felittiramirez-panuelos-verdes-aborto-argentina-mexico/

Fernández, C. (2020). Fighting for abortion rights in Latin America social movements, state allies and institutions. Routledge.

Ferree, M. M. (Ed.). (2002). Shaping abortion discourse: Democracy and the public sphere in Germany and the United States. Cambridge University Press.

Hall, S. (2010). La cultura, los medios de comunicación y el "efecto ideológico". En E. Restrepo, C. Walsh, y V. Vich (Eds.), Sin garantías: Trayectorias y problemáticas en estudios culturales (pp. 221-254). Envión editores, Instituto de Estudios Peruanos, Instituto de Estudios Sociales y Culturales y Universidad Andina Simón Bolívar.

Hernández, T. (2019). Estado laico y federalismo en México. Revista Mexicana de Sociología, 81(1), 179-208. http://www.scielo. org.mx/pdf/rms/v81n1/0188-2503-rms-81-01-179.pdf

Instituto Federal de Telecomunicaciones, IFT.(2019). Encuesta Nacional de Consumo de Contenidos Audiovisuales del 2018. http:// www.ift.org.mx/sites/default/files/contenidogeneral/ medios-y-contenidos-audiovisuales/enccal8nacional.pdf

Lamas, M. (2017). La interrupción legal del embarazo. El caso de la Ciudad de México. Fondo de Cultura Económica.

Lemaitre, J. (2013). Laicidad y resistencia: Movilización católica contra los derechos sexuales y reproductivos en América Latina. Instituto de Investigaciones Jurídicas, IIJ-Universidad Nacional Autónoma de México, UNAM.

López, J. A. (2018). Movilización y contramovilización frente a los derechos LGBT. Respuestas conservadoras al reconocimiento de los derechos humanos. Estudios Sociológicos, 36(106), 161-187. https://doi.org/10.24201/es.2018v36n106.1576

López, J. A. (2020). Aborto, contramovilización y estrategias de comunicación contra la expansión de derechos en México. Revista Interdisciplinaria de Estudios de Género de El Colegio de México, (6), 1-36. https://doi.org/10.24201/reg.v6i0.621

Maier, E. (2010). Discursos, actores y estrategias en la disputa por el significado de la vida y los derechos reproductivos. Región y Sociedad, 22(49), 201-238. http://www.scielo.org.mx/scielo. php?script=sci_arttext $\&$ pid=S1870-39252010000300008 
Maier, E. (2015). La disputa sobre el aborto en México: Discursos contrastados de personificación, derechos, la familia y el Estado. Gerencia y Políticas de Salud, 14(29), 10-24. https:// doi.org/10.11144/Javeriana.rgyps14-29.dsam

Martín Barbero, J. (1987). De los medios a las mediaciones. Comunicación, cultura y hegemonía. Gustavo Gili.

Mattoni, A. y Treré, E. (2014). Media practices, mediation processes, and mediatization in the study of social movements. Communication Theory, 24(3), 252-271. https://doi. org/10.1111/comt.12038

Morán, J. M. (2018). Religión, secularidad y activismo héteropatriarcal: ¿qué sabemos del activismo opositor a los derechos sexuales y reproductivos en Latinoamérica? Revista de Estudios de Género, La Ventana, 5(47), 97-138. http:// www.scielo.org.mx/scielo.php?script=sci_arttext\&pid $=$ S1405-94362018000100097

Pérez Bentancur, V. y Rocha-Carpiuc, C. (2020). The postreform stage: Understanding backlash against sexual policies in Latin America. Politics \& Gender, 16(1), E3. https://doi. org/10.1017/S1743923X20000069

Requena, A. (26 de diciembre de 2019). De las huelgas del 8M a "El violador eres tú": El feminismo resurge como movimiento de masas. Eldiario.es. https://www.eldiario. es/sociedad/decada-feminismo-resurgir-movimientomasas_0_978152314.html

Rohlinger, D. A. (2015). Abortion politics, mass media, and social movements in America. Cambridge University Press.

Rovira, G. (2018). El devenir feminista de la acción colectiva. Las multitudes conectadas y la nueva ola transnacional contra las violencias machistas en red. Teknokultura, 15(2), 223240. https://doi.org/10.5209/TEKN.59367

Sáez, M. y Morán, J. (2016). Sexo, delitos y pecados. Intersecciones entre religión, género, sexualidad y el derecho en América Latina. American University.

Silverstone, R. (2005). The sociology of mediation and communication. En C. Calhoun, C. Rojek y B. Turner (Eds.), The SAGE Handbook of Sociology (pp. 188-207). SAGE Publications. https://doi.org/10.4135/9781848608115.n11 
Tarrow, S. (2004). El poder en movimiento. Los movimientos sociales, la acción colectiva y la política. Alianza.

Thompson, J. (1998). Los media y la modernidad. Unta teoría de los medios de comunicación. Paidós.

Tilly, C. y Wood, L. (2010). Los movimientos sociales, 1768-2008. Desde sus orígenes hasta Facebook. Crítica.

Van Dijk, T. (2009). Discurso y poder. Contribuciones a los estudios críticos del discurso. Gedisa.

Van Dijk, T. A. (2016). Análisis crítico del discurso. Revista Austral de Ciencias Sociales, (30), 203-222. https://doi.org/10.4206/rev. austral.cienc.soc.2016.n30-10

Vázquez, F. (2007). La fe y la ciudadanía en la práctica evangélica veracruzana. Centro de Investigaciones y Estudios Superiores en Antropología Social, CIESAS.

Zaremberg, G. y Guzmán, Á. (2019). Aborto, movimientos y femocracias: Un análisis relacional. Revista Mexicana de Sociología, 81(1), 145-177. http://dx.doi.org/10.22201/ iis.01882503p.2019.1.57830 